\title{
Outcomes of pediatric severe traumatic brain injury patients treated in adult trauma centers with and without added qualifications in pediatrics - United States, 2009
}

Fernando Ovalle $\mathrm{Jr}^{1,2}$, Likang Xu¹, William S Pearson ${ }^{1}$, Bridget Spelke ${ }^{1}$ and David E Sugerman ${ }^{1 *}$

\begin{abstract}
Background: Pediatric traumatic brain injury (TBI) is an important public health problem and little is known about site of care and outcomes of children with severe TBI. Across the country, most injured children are treated in adult trauma centers (ATCs). Recent literature suggests that ATCs with added qualifications in pediatrics (ATC-AQs) can have improved outcomes for pediatric trauma patients overall. This study characterizes the population of pediatric severe TBI patients treated at ATCs and investigates the effect of treatment at ATC-AQs versus ATCs on mortality.

Methods: Using the 2009 National Trauma Data Bank, pediatric (age 0-17 years old) severe TBI (head Abbreviated Injury Scale score $\geq 3$ ) patient visits at level I and II ATCs and ATC-AQs were analyzed for patient and hospital characteristics. The primary outcome was in-patient mortality. Multivariate analysis was performed on propensity score weighted populations to investigate effect of treatment at ATC-AQs versus ATCs on survival.

Results: A total of 7,057 pediatric severe TBI patient visits in 398 level I and II trauma centers were observed, with $3,496(49.5 \%)$ at ATC-AQs and 3,561 (50.5\%) at ATCs. The mortality rate was $8.6 \%$ at ATC-AQs versus $10.3 \%$ at ATCs ( $p=0.0144$ ). After adjusting for differences in case mix, patient, and hospital characteristics, mortality was not significantly different for patients treated in ATC-AQs versus ATCs ( $\mathrm{aOR}=0.896,95 \% \mathrm{Cl}=0.629-1.277$ ). Mortality was significantly associated with age, length of hospital stay, firearm injury, GCS score, and head AIS ( $p<0.0001)$. Higher mortality odds were also associated with being uninsured ( $\mathrm{aOR}=2.102,95 \% \mathrm{Cl}=1.159-3.813)$, and the presence of additional non-TBI severe injuries ( $\mathrm{aOR}=1.93695 \% \mathrm{Cl}=1.175-3.188)$.

Conclusions: After defining comparable populations, this study demonstrated no significant difference in mortality for pediatric severe TBI patients treated at ATC-AQs versus ATCs. Being younger, uninsured, and having severe injuries was associated with increased mortality. This study is limited by the exclusion of transferred patients and potentially underestimates differences in outcomes. Further research is needed to clarify the role of ATC additional pediatric qualifications in the treatment of severe TBI.
\end{abstract}

Keywords: Traumatic brain injury; Pediatrics; Trauma centers; Mortality

\footnotetext{
* Correspondence: ggi4@cdc.gov

'Division of Injury Response, National Center for Injury Prevention and Control, Centers for Disease Control and Prevention, 4470 Buford Highway NE, MS-F62, Atlanta, GA 30341, USA

Full list of author information is available at the end of the article
} 


\section{Background}

In the United States, traumatic brain injury (TBI) is the single leading cause of injury-related death and acquired disability among children and young adults, affecting both sexes and all economic, racial, and social backgrounds (Coronado et al. 2011; Keenan and Bratton 2006; Langlois et al. 2005). Between 2002-2006, for pediatric patients aged $0-19$ years old there were nearly 700,000 TBIs alone or in conjunction with other injuries or conditions resulting in TBI-related emergency department (ED) visits, hospitalizations, and deaths (Faul et al. 2010). Most TBIs are mild (Glasgow Coma Scale [GCS] score 13-15); however, up to a quarter are moderate (GCS 9-12) or severe (GCS 3-8) and responsible for a disproportionately high degree of morbidity and mortality (National Center for Injury Prevention and Control 2003). Severely injured children are known to face higher rates of in-hospital mortality, longer hospital stays, and require extensive and specialized rehabilitation to address major cognitive sequelae (Densmore et al. 2006; Rivara et al. 2011; Slomine et al. 2006; Tepas et al. 2009; Yeates et al. 2004). Pediatric TBI also contributes to the healthcare cost burden in the United States, accounting for over $\$ 1$ billion in total annual hospital charges (Schneier et al. 2006). With high rates of TBI-related morbidity and mortality contributing to many lost years of productive life, both the financial and human cost of pediatric TBI make it a significant public health problem.

Trauma systems in the U.S. evolved to improve the triage and treatment of injured patients, ultimately resulting in decreased mortality at trauma centers compared to non-trauma centers (MacKenzie et al. 2006). Pediatric trauma patients can have needs that differ from those of adult trauma patients, and the lack of pediatric-specific personnel and equipment at adult trauma centers (ATCs) that care for injured children has been documented (Athey et al. 2001; Gausche-Hill et al. 2007). On the other hand, pediatric trauma centers (PTCs) are specifically equipped and staffed with specialty-trained caregivers to provide optimal care for injured children (American College of Surgeons Committee on Trauma 2006). While some authors dispute outcome differences between ATCs and PTCs (Fortune et al. 1992; Jubelirer et al. 1990; Kaufmann et al. 1989; Knudson et al. 1992; Osler et al. 2001; Rhodes et al. 1993), other studies have demonstrated improvement in morbidity and mortality when pediatric trauma patients are treated at PTCs (Densmore et al. 2006; Mooney et al. 2006; Potoka et al. 2001; Pracht et al. 2008).

Due to the shortage of PTCs as well as geographic distributions limiting access to care at PTCs in many areas of the country (Nance et al. 2009), the majority of pediatric trauma patients in the U.S. receive care at
ATCs (Segui-Gomez et al. 2003). PTCs alone cannot fully address the care of all injured children; instead, they must work in partnership with ATCs to optimize the system of care of pediatric trauma patients (Athey J et al. 2001). One development to the trauma system classification scheme is the ability of adult trauma centers to gain added qualifications in pediatrics (ATC-AQs) and therefore offer more directed care for pediatric patients. While the literature on ATC-AQs is limited, some studies have demonstrated improved outcomes for pediatric trauma patients compared to ATCs alone (Oyetunji et al. 2011; Potoka et al. 2000) and comparable outcomes with PTCs (Potoka et al. 2000).

Although it has been proposed that ATC-AQs improve overall outcomes for pediatric trauma patients compared to ATCs, little is known about the optimal triage strategy and the resulting outcomes of children with TBI, especially those with severe TBI who need high acuity care the most. Current guidelines and recommendation standards cite the limited evidence available in this area, especially on a national level (Adelson et al. 2003; Kochanek et al. 2012); therefore, further understanding of the effect of trauma systems on the care of children with severe TBI is needed to reduce the impact of this important public health issue. In order to address this gap, the objectives of our study were to characterize the population of pediatric severe TBI patients treated at ATC-AQs and ATCs, to investigate the effect of treatment at ATC-AQs versus ATCs on patient mortality and to inform pediatric patient transport decision-making, following severe TBI, in the absence of a PTC.

\section{Methods}

The study design was a retrospective secondary analysis using the 2009 National Trauma Data Bank (NTDB) Research Data Set (RDS). This dataset is managed by the American College of Surgeons (ACS) and, in 2009, collected trauma visits voluntarily submitted by 682 U.S. trauma centers. The study population was comprised of visits of pediatric patients who were aged 0-17 years old with a diagnosis of severe TBI (defined by head maximum Abbreviated Injury Scale [AIS] score $\geq 3$ ). TBI was identified using International Classification of Diseases, $9^{\text {th }}$ Revision Clinical Modification (ICD-9-CM) codes obtained from the NTDB. The Centers for Disease Control and Prevention (CDC) definition of TBI was used (Faul et al. 2010) and included the following codes: fracture of the vault or base of skull (800.0-801.9), other and unqualified multiple fractures of the skull (803.0804.9), intracranial injury, including concussion, contusion, laceration, and hemorrhage (850.0-854.1), injury to optic nerve and pathways (950.1-950.3), shaken infant syndrome (995.55), and head injury, unspecified (959.01). 
Patients who were dead on arrival or expired in the ED after failed resuscitation, patient visits at trauma centers with unknown level, and those with unknown sex were excluded (Figure 1). The location of care at a PTC, an ATC-AQ or an ATC without pediatric sub-specialization was investigated. Using NTDB facility variables (American College of Surgeons Committee on Trauma 2008), a PTC was defined as having an ACSverified adult trauma center or state-designated adult trauma center level of "not applicable" with additional level I or II ACS pediatric verification or level I or II state pediatric designation. An ATC was defined as a level I or II ACS-verified adult trauma center or a level I or II state-designated adult trauma center. An ATC-AQ was defined as a level I or II ACS-verified adult trauma center with additional ACS pediatric verification or a level I or II state-designated adult trauma center with additional state pediatric designation. In two cases where

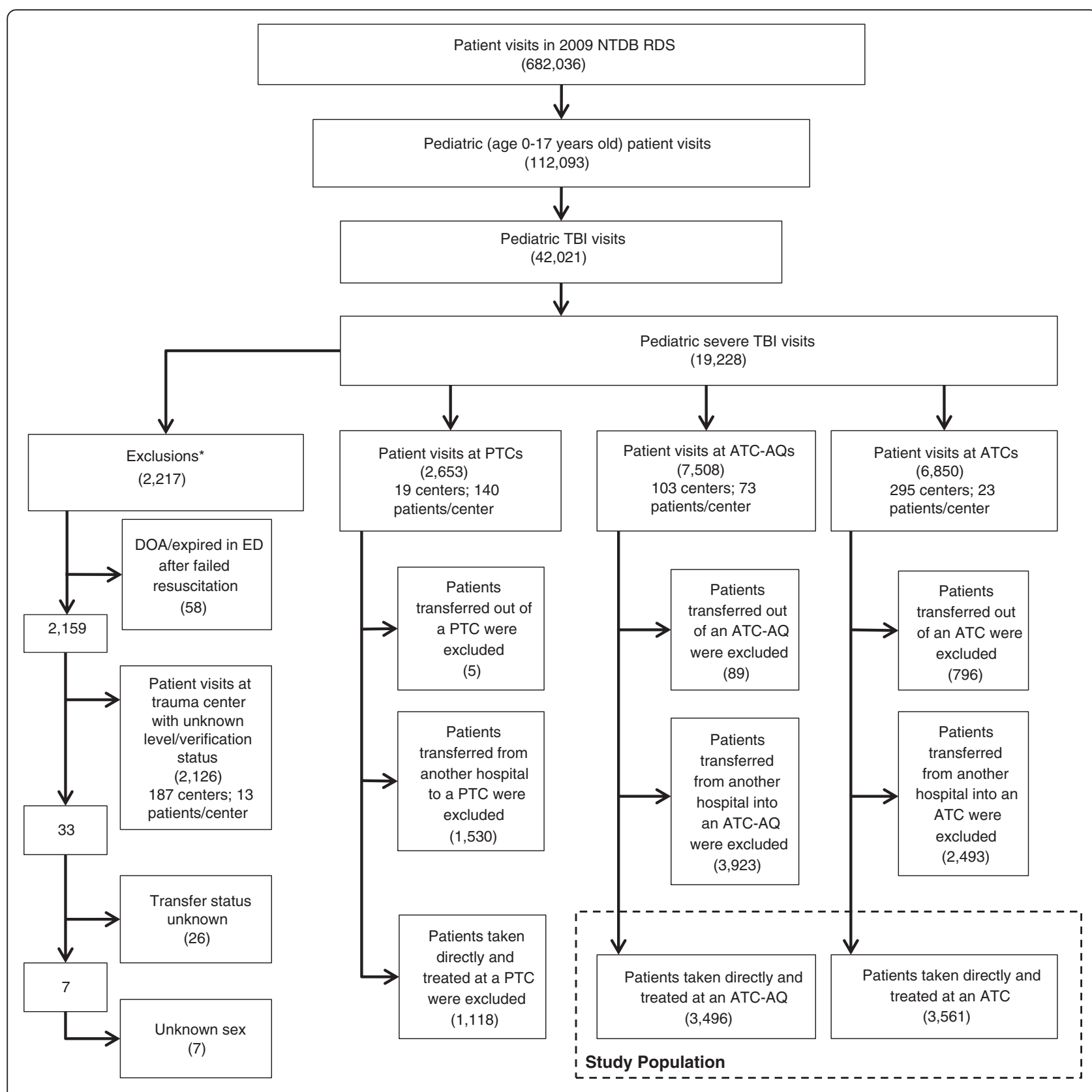

*Subsets of Exclusions are mutually exclusive

Figure 1 Derivation of pediatric severe TBI study population using 2009 National Trauma Data Bank (NTDB) Research Data Set (RDS). 
ACS verification and state designation were both present and differed on level of trauma center, the ACS specification was used. All patients transferred into ATC-AQs and ATCs were excluded from analysis in order to minimize bias arising from severely injured patients who were transferred to a higher level or more specialized centers. Transfers out were excluded as their outcomes cannot be determined in the NTDB (Figure 1). Repeated analysis on transfers alone and including these subpopulations revealed similar results (data not shown). Lastly, because pediatric verification/designations are only available for level I or II centers in the NTDB, all visits seen at non-level I or II adult trauma centers were excluded.

Definitions of the variables examined are described in the NTDB Data Dictionary (American College of Surgeons Committee on Trauma 2008). The primary outcome was in-hospital mortality. Unadjusted analysis included the secondary outcome measures length of stay (LOS) in days, ICU days, ventilator days, hospital complications (any medical complication during the hospital stay as defined by the NTDB), and hospital discharge disposition among survivors (classified as home with no home services/extra care versus rehabilitation/other care facilities [including short-, long-, and intermediate-care facilities, home with home health services, and hospice] as well as other/unknown [including left against medical advice]). Other variables included in both unadjusted and adjusted analyses were age (infants/toddlers aged 03 years old, preschool/young children aged 4-8 years old, preadolescents aged 9-13 years old, and adolescents aged 14-17 years old), sex, race/ethnicity (white, African American, Hispanic, other [including Asian, Native American, and Hawaiian/Pacific Islander] and unknown), trauma center level (I or II), Injury Severity Score (ISS) as determined in the NTDB by ICDMAP-90 calculation (severe [ISS >15] or non-severe [ISS $\leq 15]$ ), emergency department Glasgow Coma Scale (ED GCS $3-4,5-6,7-8,>8$ ), insurance status (commercial and other, self-pay, Medicaid, and unknown), mechanism of injury (falls, firearms, motor vehicle accident [MVA], struck by/against, all other mechanisms of injury described by the NTDB, and unknown), head AIS (3, 4, 5, or 6), TBI type (subdural hematoma $(\mathrm{SDH})$, subarachnoid hemorrhage $(\mathrm{SAH})$ or extradural hematoma (EDH); unspecified intracranial hemorrhage (ICH); cerebral laceration or contusion; other intracranial injury; closed head injury without mention of intracranial injury; or "other" for cases not meeting criteria defined above), and whether the patient had isolated versus polytraumatic severe TBI. In order to better study the effect of other severe injuries on outcomes, the polytraumatic severe TBI population was further subdivided into non-severe polytraumatic (severe TBI plus any injury in a body region other than the head with AIS score of $<3$ ) and severe polytraumatic (severe TBI plus any injury in a body region other than the head with AIS score of $\geq 3$ ) groups.

All data analysis was performed using SAS 9.3 (SAS Institute Inc., Cary, NC). Unadjusted bivariate analyses were performed on patient and injury characteristic variables in both ATC and ATC-AQ groups. Two-tailed independent $t$ tests were used to compare continuous variables and $X^{2}$ tests were used to compare categorical variables. Multiple imputation techniques were used to preserve sample size and account for missing values in our sample. Data were missing for fewer than $5 \%$ of patient visits with the exception of insurance $(12.6 \%$ missing) and ISS (8.9\% missing data). Ten imputed data sets were created. For each data set, generalized estimating equations (GEEs) were used to adjust for clustering within sites (MacKenzie et al. 2006; Roudsari et al. 2008). Data sets were analyzed in parallel and the results were combined using standard techniques (Roudsari et al. 2008).

To account for potential confounding factors and study the effect of treatment center type on outcome, the inverse probability of treatment weighting, or propensity score weighting, was used to create balanced and comparable populations in our two study groups (patients treated at ATCs and ATC-AQs) (Cudnik et al. 2009; MacKenzie et al. 2006). Including the primary outcome, the following variables were included in the development of the propensity score: age, sex, race, insurance status, trauma center level, ED GCS, mechanism of injury, presence of TBI polytrauma, head AIS, TBI type, and length of stay (LOS).

Multivariate logistic regression was used to examine the effect of independent variables on patient survival to discharge. Adjusted odds ratio (aOR) and 95\% confidence interval (CI) for in-hospital mortality were calculated after adjusting for sex, age, race/ethnicity, insurance, trauma center level, ED GCS, head AIS, mechanism of injury, presence of TBI polytrauma and TBI type. Age, LOS and GCS variables were used as continuous variables in the multivariate analysis instead of their categorical breakdowns. Significance level for all statistical tests was set at $p<0.05$.

\section{Results}

Out of 682,036 trauma center patient visits reported in the 2009 NTDB RDS, there were 112,093 (16.4\%) patient visits by pediatric patients who were aged $0-17$ years old (Figure 1). Out of these, a total of 42,021 visits (37.5\% of total pediatric patient visits) were found that included a TBI diagnosis, and 19,228 (45.8\% of total pediatric TBI visits) were found to have severe TBI. There were 2,217 patient visits (11.5\% of pediatric severe TBI visits) excluded from our study due to death on arrival or prior 
Table 1 Patient and injury characteristics of pediatric severe TBI patient visits treated in ATC-AQs and ATCs

\begin{tabular}{|c|c|c|c|c|c|}
\hline & $\begin{array}{c}\text { ATC-AQ } \\
n(\%) \\
(\mathrm{N}=3,496)\end{array}$ & $\begin{array}{c}\text { ATC } \\
n(\%) \\
(\mathrm{N}=3,561)\end{array}$ & $\begin{array}{c}\text { Total } \\
\text { n (\%) } \\
(\mathrm{N}=7,057)\end{array}$ & $\begin{array}{l}\text { Odds Ratio }^{*} \\
(95 \% \mathrm{Cl})\end{array}$ & $\mathrm{P}_{\text {value }}{ }^{*}$ \\
\hline \multicolumn{6}{|l|}{ Sex } \\
\hline Female & $1,215(34.8)$ & $1,144(32.1)$ & 2,359 (33.4) & 1.0 (reference) & \\
\hline Male & $2,281(65.2)$ & $2,417(67.9)$ & 4,698 (66.6) & $0.889(0.805-0.981)$ & 0.0202 \\
\hline \multicolumn{6}{|l|}{ Age group (years) } \\
\hline $0-3$ & $1,154(33.0)$ & $681(19.1)$ & $1,835(26.0)$ & 1.0 (reference) & \\
\hline $4-8$ & $604(17.3)$ & $426(12.0)$ & $1,030(14.6)$ & $0.837(0.716-0.978)$ & 0.0279 \\
\hline $9-13$ & $618(17.7)$ & $539(15.1)$ & $1,157(16.4)$ & $0.677(0.583-0.786)$ & $<.0001$ \\
\hline $14-17$ & $1,120(32.0)$ & $1,915(53.8)$ & $3,035(43.0)$ & $0.345(0.306-0.389)$ & $<.0001$ \\
\hline \multicolumn{6}{|l|}{ Race/Ethnicity } \\
\hline White & $1,895(54.2)$ & $2,027(56.9)$ & $3,922(55.6)$ & 1.0 (reference) & \\
\hline Black & $606(17.3)$ & $500(14.0)$ & $1,106(15.7)$ & $1.296(1.134-1.482)$ & 0.0002 \\
\hline Hispanic & $622(17.8)$ & $648(18.2)$ & $1,270(18.0)$ & $1.027(0.905-1.165)$ & 0.6983 \\
\hline Other & $259(7.4)$ & $251(7.0)$ & $510(7.2)$ & $1.104(0.918-1.327)$ & 0.3005 \\
\hline Unknown & $114(3.3)$ & $135(3.8)$ & $249(3.5)$ & $0.903(0.699-1.168)$ & 0.4720 \\
\hline \multicolumn{6}{|l|}{ Insurance } \\
\hline Commercial and other & $1,709(48.9)$ & $1,941(54.5)$ & $3,650(51.7)$ & 1.0 (reference) & \\
\hline Self Pay & $233(6.7)$ & $314(8.8)$ & $547(7.8)$ & $0.843(0.703-1.011)$ & 0.0660 \\
\hline Medicaid & $1,047(29.9)$ & $925(26.0)$ & $1,972(27.9)$ & $1.286(1.152-1.435)$ & $<.0001$ \\
\hline Unknown & $507(14.5)$ & $381(10.7)$ & $888(12.6)$ & $1.511(1.304-1.752)$ & $<.0001$ \\
\hline \multicolumn{6}{|l|}{ Trauma center level } \\
\hline Level I & $2,482(71.0)$ & $2,228(62.6)$ & $4,710(66.7)$ & 1.0 (reference) & \\
\hline Level ॥ & $1,014(29.0)$ & $1,333(37.4)$ & $2,347(33.3)$ & $0.683(0.618-0.754)$ & $<.0001$ \\
\hline \multicolumn{6}{|l|}{ ED GCS } \\
\hline $3-4$ & $670(19.2)$ & $714(20.1)$ & 1,384 (19.6) & $0.913(0.81-1.028)$ & 0.1361 \\
\hline $5-6$ & $94(2.7)$ & $135(3.8)$ & $229(3.2)$ & $0.677(0.518-0.887)$ & 0.0045 \\
\hline $7-8$ & $111(3.2)$ & $156(4.4)$ & $267(3.8)$ & $0.692(0.539-0.889)$ & 0.0038 \\
\hline$>8$ & 2,499 (71.5) & $2,431(68.3)$ & $4,930(69.9)$ & 1.0 (reference) & \\
\hline Unknown & $122(3.5)$ & $125(3.5)$ & $247(3.5)$ & $0.949(0.735-1.226)$ & 0.6962 \\
\hline \multicolumn{6}{|l|}{ Head AIS } \\
\hline 3 & $1,125(32.2)$ & $1,162(32.6)$ & $2,287(32.4)$ & 1.0 (reference) & \\
\hline 4 & 2,021 (57.8) & $1,873(52.6)$ & $3,894(55.2)$ & $1.115(1.005-1.236)$ & 0.0399 \\
\hline 5 & $345(9.9)$ & $515(14.5)$ & $860(12.2)$ & $0.692(0.590-0.811)$ & $<.0001$ \\
\hline 6 & $5(0.1)$ & $11(0.3)$ & $16(0.2)$ & $0.469(0.163-1.356)$ & 0.2098 \\
\hline \multicolumn{6}{|l|}{ ISS Score } \\
\hline ISS $<15$ & $847(24.2)$ & $875(24.6)$ & $1,722(24.4)$ & 1.0 (reference) & \\
\hline ISS $>15$ & 2,329 (66.6) & $2,378(66.8)$ & $4,707(66.7)$ & $1.012(0.906-1.130)$ & 0.8437 \\
\hline Unknown & $320(9.2)$ & $308(8.6)$ & $628(8.9)$ & $1.073(0.894-1.289)$ & 0.4560 \\
\hline \multicolumn{6}{|l|}{ Mechanism of injury } \\
\hline Falls & $1,028(29.4)$ & $858(24.1)$ & $1,886(26.7)$ & 1.0 (reference) & \\
\hline Firearms & $108(3.1)$ & $185(5.2)$ & $293(4.2)$ & $0.487(0.378-0.628)$ & $<.0001$ \\
\hline Motor vehicles & $1,303(37.3)$ & $1,433(40.2)$ & $2,736(38.8)$ & $0.759(0.675-0.854)$ & $<.0001$ \\
\hline Struck by/against & $328(9.4)$ & 407 (11.4) & 735 (10.4) & $0.673(0.567-0.798)$ & $<.0001$ \\
\hline
\end{tabular}


Table 1 Patient and injury characteristics of pediatric severe TBI patient visits treated in ATC-AQs and ATCs (Continued)

\begin{tabular}{|c|c|c|c|c|c|}
\hline Other & $728(20.8)$ & $678(19.0)$ & $1,406(19.9)$ & $0.896(0.780-1.029)$ & 0.1289 \\
\hline Unknown & $1(0.0)$ & $0(0.0)$ & $1(0.0)$ & & \\
\hline \multicolumn{6}{|l|}{ TBI type } \\
\hline $\mathrm{SAH}, \mathrm{SDH}, \mathrm{EDH}$ & $811(23.2)$ & $788(22.1)$ & $1,599(22.7)$ & $1.171(1.036-1.325)$ & 0.0121 \\
\hline Intracranial Hemm (other and unspecified) & $107(3.1)$ & $122(3.4)$ & $229(3.2)$ & $0.998(0.762-1.308)$ & 1.0000 \\
\hline Cerebral Laceration and Contusion & $246(7.0)$ & $260(7.3)$ & $506(7.2)$ & $1.077(0.891-1.302)$ & 0.4680 \\
\hline Other Intracranial Injury & $169(4.8)$ & $118(3.3)$ & $287(4.1)$ & $1.630(1.274-2.086)$ & 0.0001 \\
\hline No Mention of Intracranial Injury & $853(24.4)$ & $782(22.0)$ & $1,635(23.2)$ & $1.242(1.099-1.403)$ & 0.0005 \\
\hline Other & $1,310(37.5)$ & $1,491(41.9)$ & $2,801(39.7)$ & 1.0 (reference) & \\
\hline \multicolumn{6}{|l|}{ Presence of severe TBI polytrauma ${ }^{\dagger}$} \\
\hline TBI only & $1,265(36.2)$ & $1,140(32.0)$ & $2,405(34.1)$ & 1.0 (reference) & \\
\hline $\mathrm{TBI}+$ non-Severe Injury & $1,500(42.9)$ & $1,580(44.4)$ & $3,080(43.6)$ & $0.856(0.769-0.952)$ & 0.0043 \\
\hline $\mathrm{TBI}+$ Severe Injury & $731(20.9)$ & $841(23.6)$ & $1,572(22.3)$ & $0.783(0.690-0.890)$ & 0.0002 \\
\hline \multicolumn{6}{|l|}{ Hospital complications $^{\neq}$} \\
\hline No & $1,716(49.1)$ & $1,448(40.7)$ & $3,164(44.8)$ & 1.0 (reference) & \\
\hline Yes & $333(9.5)$ & $423(11.9)$ & $756(10.7)$ & $0.664(0.566-0.779)$ & $<.0001$ \\
\hline Unknown & $1,447(41.4)$ & $1,690(47.5)$ & $3,137(44.5)$ & $0.722(0.654-0.798)$ & $<.0001$ \\
\hline \multicolumn{6}{|l|}{ Discharge disposition $^{\S}$} \\
\hline Home (without extra care) & $2,621(82.0)$ & 2,382 (74.6) & $5,003(78.3)$ & 1.0 (reference) & \\
\hline Rehabilitation/other care facility" & $512(16.0)$ & $674(21.1)$ & $1,186(18.6)$ & $0.690(0.608-0.784)$ & $<.0001$ \\
\hline Other/unknown & $64(2.0)$ & $139(4.4)$ & $203(3.2)$ & $0.418(0.310-0.566)$ & $<.0001$ \\
\hline ICU Days (Mean \pm SE) & $4.84(0.16)$ & $5.01(0.17)$ & $4.93(0.12)$ & & $0.4684^{* *}$ \\
\hline Length of stay (days) (Mean \pm SE) & $6.17(0.16)$ & $6.09(0.17)$ & $6.13(0.12)$ & & $0.7369^{* *}$ \\
\hline Alive (Mean \pm SE) & $6.40(0.17)$ & $6.44(0.19)$ & $6.42(0.13)$ & & $0.8665^{* *}$ \\
\hline Died (Mean \pm SE) & $3.73(0.4)$ & $3.04(0.27)$ & $3.35(0.23)$ & & $0.1574^{* *}$ \\
\hline Ventilator days (Mean \pm SE) & $6.09(0.29)$ & $5.57(0.26)$ & $5.81(0.19)$ & & $0.1728^{* *}$ \\
\hline Mortality & $299(8.6)$ & $366(10.3)$ & $665(9.4)$ & $0.816(0.695-0.959)$ & 0.0144 \\
\hline
\end{tabular}

Data are reported as counts, percentages (\%), and mean $+\mathrm{SE}$.

${ }^{*}$ Calculated by $X^{2}$ test; ${ }^{* *}$ Calculated by two-tailed independent $t$-test.

${ }^{\dagger}$ Non-severe polytraumatic $\mathrm{TBI}=$ severe $\mathrm{TBI}$ plus injury in body region other than head with AIS score $<3$, severe polytraumatic $\mathrm{TBI}=$ severe $\mathrm{TBI}$ plus injury in body region other than head with AIS score $\geq 3$.

${ }^{*}$ Defined by NTDB as any medical complication occurring during hospital stay.

${ }^{5}$ Disposition does not include deaths $(n=665)$.

"Other care facilities include short-, long-, and intermediate-care facilities, home with home health services/extra care, and hospice.

to ED discharge, unknown level of trauma center, unknown transfer status, or unknown patient sex. Patient visits at PTCs $(2,653)$, including transfers, were also excluded. Our final study population drew from 14,358 pediatric severe TBI patient visits seen at 398 level I and II trauma centers. All patients transferred into or out of an ATC-AQ or ATC were excluded. Our final study population included 7,057 severe pediatric TBI visits (Figure 1).

Of 7,057 pediatric severe TBI patient visits, 3,496 (49.5\%) were treated at ATC-AQs and 3,561 (50.5\%) were at ATCs (Table 1). Compared to ATCs, ATC-AQs were found to have an overall younger population $(p<0.0001)$, more African American patient visits $(p=$ $0.0002)$, more Medicaid patient visits $(p<0.0001)$, and more patient visits at level I centers $(p<0.0001)$. With respect to mechanism of injury, ATC-AQs were found to have significantly fewer firearm-related $(p<0.0001)$, motor vehicle $(p<0.0001)$ and struck by/against visits $(p$ $<0.0001)$ than ATCs. Compared to ATCs, ATC-AQs were found to have fewer visits with severe polytraumatic TBI $(p=0.0002)$ and more visits with other intracranial injury $(p=0.0001)$. No statistically significantly differences between the two categories of centers were noted by sex or ISS (Table 1).

The study population included 665 deaths. More specifically, ATC-AQs were found to have 299 deaths compared to 366 deaths at ATCs $(8.6 \%$ vs. $10.3 \%$ mortality rate, respectively; $p=0.0144$; Table 1 ). Patients treated at ATC-AQs were less likely to have in-hospital 
complications $(p<0.0001)$. No significant difference in the mean length of stay, in the mean number of ICU days, and the mean number of ventilator days was seen between the centers. Propensity score adjustment created equal populations for all patient and injury characteristics except insurance status, which remained significantly different for both groups (data not shown).

After adjusting for differences in case mix using propensity scoring, multiple logistic regression analysis adjusted for treatment center type and all variables in Table 2 found no significant difference in mortality between ATC-AQs and ATCs $(\mathrm{aOR}=0.896 ; 95 \% \mathrm{CI}$ $0.629-1.277$ ) (Table 2). Mortality odds were significantly associated with being younger, having a shorter length of stay, being uninsured, having a firearm injury, and the presence of an additional severe traumatic injury (Table 2). Having a fall and a struck by/against injury were associated with lower mortality odds. Patient visits that were self-pay had significantly higher mortality than insured visits $(\mathrm{aOR}=2.102$; 95\% CI 1.159-3.813). Mortality was also higher with increasing head AIS and decreasing GCS score (Table 2).

\section{Discussion}

This study characterizes children who sustained a severe TBI and were treated at level I and II adult trauma centers either with or without added qualifications in pediatrics and provides a large adjusted multivariate analysis of in-hospital mortality by type of adult trauma center. Overall, ATC-AQs had a younger patient population, fewer uninsured visits, and more fall-related visits than ATCs. Consistent with prior studies, mortality odds after severe TBI are higher for uninsured patients (Haider et al. 2008; Rosen et al. 2009) and firearm injuries (Asemota et al. 2013; Deans et al. 2013; Sugerman et al. 2012). As expected, mortality is associated with injury severity indexes including head AIS and ED GCS (Keenan and Bratton 2006). Younger age and the presence of a severe polytraumatic injury were also associated with increased mortality odds. However, children treated at ATC-AQs were no more likely to die than children treated at ATCs. In this light, our results substantiate previous findings of equivalency in survival outcomes between pediatric-specialized and non-pediatric-specialized adult trauma centers for certain populations of injured pediatric patients (Fortune et al. 1992; Jubelirer et al. 1990; Kaufmann et al. 1989; Knudson et al. 1992; Osler et al. 2001; Rhodes et al. 1993) and indicates that there is no increased risk of in-patient mortality for severe pediatric TBI patients triaged to an adult trauma center.

The highest level of care for injured children in U.S. is the stand-alone PTC, which has the full array of pediatric specialists and services, as well as an institutional-wide commitment to pediatric injury education, research, and prevention. While multiple studies have demonstrated PTCs' favorable effects on mortality rates (Densmore et al. 2006; Mooney et al. 2006; Potoka et al. 2001; Pracht et al. 2008), most pediatric trauma patients are treated in ATCs (Segui-Gomez et al. 2003). According to the American College of Surgeons Committee on Trauma, to gain the "added qualifications in pediatrics" label, an ATC must admit $\geq 100$ children $<15$ years of age; have a pediatric surgeon credentialed for pediatric trauma care; and have a pediatric emergency department/intensive care area with appropriate resuscitation equipment (American College of Surgeons Committee on Trauma 2006). As opposed to general trauma managed by pediatric general surgeons, children with severe neurotrauma often require pediatric neurosurgery and neurointensivists care (Kochanek et al. 2012) only found in PTCs (American College of Surgeons Committee on Trauma 2006). The lack of specialized pediatric neurological care at both ATCs and ATC-AQs may explain why no difference in mortality was seen among pediatric severe TBI patients treated at these centers.

The Brain Trauma Foundation (BTF) has outlined the acute management of pediatric severe TBI patients (Adelson et al. 2003; Kochanek et al. 2012) and makes three levels of recommendations - standards, guidelines, and options. As noted by the BTF, there is currently insufficient evidence to establish a standard with regards to the triage of pediatric severe TBI patients. At the guideline level, the BTF recommends that in a metropolitan area, children with severe TBI should be transported directly to a PTC if available. At the option level, they suggest triage to an ATC-AQ in preference to a level I or II ATC without added qualifications. These recommendations were evaluated as "weak" by the BTF, with the option to preferentially triage pediatric severe TBI patients to ATC-AQs over ATCs primarily based on the availability of a single retrospective study (Potoka et al. 2000). This study, which did not account for differences in baselines characteristics between groups or utilize multivariate statistics, demonstrated higher survival for severe TBI patients treated in PTCs or ATC-AQs than those in ATCs across Pennsylvania. Another study which was not included in the BTF evidence list utilized the 2002-2006 NTDB and suggested a lower mortality for pediatric severe TBI patients treated at Level I ATC-AQs compared to Level I ATCs, though this result only approached significance $(p=0.05)$ (Oyetunji et al. 2011). Three factors likely affected these mortality differences compared to our results: the omission of children with severe TBI treated at level II ATCs (nearly $40 \%$ of our total cases), our use of the CDC definition of severe TBI (Oyetunji et al. relied on GCS $>8$ ) and the use of propensity score weighting to create comparable populations. 
Table 2 Multivariate model of pediatric severe TBI patient mortality

Age
Length of hospital stay (days)
GCS score

\section{Trauma center}

\author{
ATC-AQ
}

ATC

\section{Sex}

Female

Male

\section{Race/Ethnicity}

White
Black
Hispanic
Other

Insurance

Commercial and other

Self Pay

Medicaid

Trauma center level

Level I

Level II

Head AIS

3

4

5

6

Mechanism of injury

Falls

Firearms

Motor vehicles

Struck by/against

Other

\section{TBI type}

$\mathrm{SAH}, \mathrm{SDH}, \mathrm{EDH}$

Intracranial Hemm (other and unspecified)

Cerebral Laceration and Contusion

Other Intracranial Injury

No Mention of Intracranial Injury

Other

\section{Presence of severe TBI polytrauma}

$$
\begin{aligned}
& \text { TBI only } \\
& T B I+\text { non-severe injury } \\
& T B I+\text { Severe injury }
\end{aligned}
$$

aOR (95\% Cl)

$P$ value

$0.936(0.907-0.966)$

$<.0001$

$0.821(0.762-0.883)$

$<.0001$

$0.633(0.600-0.668)$

$<.0001$

1.0 (reference)

$0.896(0.629-1.277)$

0.5446

1.0 (reference)

$1.249(0.898-1.738)$

1.0 (reference)

$1.562(0.967-2.524)$

0.0683

$1.284(0.876-1.881)$

0.1998

$1.914(0.986-3.714)$

0.0550

$$
\begin{gathered}
1.0 \text { (reference) } \\
2.102(1.159-3.813)
\end{gathered}
$$

0.0145

$1.241(0.824-1.870)$

0.3006

1.0 (reference)

$1.155(0.797-1.675)$

0.4471

1.0 (reference)

4.113 (2.406-7.033)

$<.0001$

32.231 (17.580-59.094)

$<.0001$

22.641 (2.521-203.370)

0.0053

$0.333(0.173-0.644)$

0.0011

7.780 (3.493-17.328)

$<.0001$

$1.251(0.807-1.940)$

0.3175

0.399 (0.194-0.821)

0.0125

1.0 (reference)

$0.797(0.525-1.212)$

0.2891

$1.024(0.446-2.352)$

0.9555

$0.929(0.541-1.595)$

0.7881

1.675 (0.906-3.098)

0.1001

1.175 (0.689-2.001)

0.5538

1.0 (reference)

1.0 (reference)

0.681 (0.428-1.083)

0.1043

1.936 (1.175-3.188)

0.0095 
While the literature regarding the triage of pediatric severe TBI patients to ATC-AQs versus ATCs is limited, if there are no differences in mortality between two types of centers, the ultimate triage destination decision should be made in conjunction with current guidelines. The CDC Guidelines for Field Triage of Injured Patients (Sasser et al. 2012) recommends transport of all patients with moderate or severe TBI $(\mathrm{GCS} \leq 13)$ to the highest level of care within the trauma system, regardless of AQ designation. Further studies on outcomes by triage decision are warranted to inform the design of pediatric trauma care delivery systems. Facilities treating children injured with severe TBI should have available prompt CT scanning, neurosurgical care, and the ability to monitor intracranial pressure and manage intracranial hypertension. Certainly, centers with added pediatric specialization have added benefits for many subpopulations of injured children, specifically those with abdominal blunt-force injuries, for whom triaging to the highest level of pediatric specialized care available is more widely cited (Densmore et al. 2006; Mooney et al. 2006; Oyetunji et al. 2011; Potoka et al. 2001; Potoka et al. 2000; Pracht et al. 2008).

This study has several limitations. The NTDB includes only in-hospital outcomes, not capturing long-term disability for those discharged or transferred out and therefore limiting our analysis to in-patient mortality and potentially underestimating differences in outcomes. Stand-alone PTCs were not well represented in this voluntary database. Although it was assumed that with specialized pediatric neurosurgical and intensivist coverage that patient outcomes would be improved in PTCs, targeted research is lacking, and it remains the case that most pediatric trauma patients are treated in ATCs. Our study does not address the quality or standard of care at ATCs: namely, if the differing facility types are equally effective or equally ineffective in their treatment of this pediatric population. Further studies are needed to determine whether treatment at ATC-AQs provides a survival advantage to patients with severe TBI by reducing long-term disability. Finally, the NTDB-RDS is a retrospective and voluntary visit-based database and the variation in completeness between centers could lead to potential bias. Furthermore, the RDS is a nonrepresentative sample limiting the generalizability of these results. Despite these well-established limitations of the NTDB, to our knowledge, this is the first study that determines survival outcomes by ATC type with advanced statistical techniques to address the concerns of missing data, clustering by facility and the non-random distribution of cases between center types.

\section{Conclusion}

Pediatric severe TBI patient visits at ATC-AQs have similar in-hospital survival odds relative to ATCs.
Consistent with prior studies, mortality odds after severe TBI are higher for uninsured patients, younger children, firearm injuries, and the presence of an additional severe traumatic injury. When lack of access to care at a PTC necessitates a triage decision between different types of adult trauma centers, these findings support prioritizing patient triage to the highest level center available, consistent with the CDC Guidelines for Field Triage of Injured Patients (Sasser et al. 2012). These findings are limited by the exclusion of severe TBI patients transferred to another facility for treatment. Though this enables the development of comparable patient groups, it increases the potential for underestimating differences in outcomes. Ultimately, ongoing research and surveillance efforts are needed to improve pediatric trauma triage in the U.S.

\section{Abbreviations \\ TBI: Traumatic brain injury; ATCs: Adult trauma centers; ATC-AQs: Adult trauma centers with added qualifications in pediatrics; PTCs: Pediatric trauma centers; NTDB: National Trauma Data Bank; AIS: Abbreviated Injury Scale; ISS: Injury Severity Score; CDC: Centers for Disease Control and Prevention.}

\section{Competing interests}

Financial interest

The authors do not have a financial or proprietary interest in a product, method, or material or lack thereof.

Financial support

All authors: Centers for Disease Control and Prevention. Ovalle \& Spelke: Work was completed as part of the CDC Experience, a one-year fellowship in applied epidemiology at CDC made possible by a public/private partnership supported by a grant to the CDC Foundation from External Medical Affairs, Pfizer Inc.

\section{Competing interests}

The authors declare that they have no competing interests.

\section{Authors' contributions}

DS designed the study, supervised the statistical analysis and oversaw the development of the manuscript. WP contributed to the conception and design of the study, interpretation of the analysis and revision of the manuscript. FO contributed to the acquisition of the data, the development of the research protocol and the development of the manuscript. LX contributed to the data acquisition, data management and statistical analysis and contributed to the drafting and revising the manuscript. BS contributed to interpreting the results and critical revision of the analysis and manuscript. All authors read and approved the final manuscript.

\section{Acknowledgement}

Previous presentation

Oral presentation at the 12th Annual John M. Templeton Jr. Pediatric Trauma Symposium; Philadelphia, PA

\section{Disclaimer}

The findings and conclusions in this report are those of the authors and do not necessarily represent the official position of the Centers for Disease Control and Prevention. The National Trauma Data Bank remains the full and exclusive copyrighted property of the American College of Surgeons. The American College of Surgeons is not responsible for any claims arising from works based on the original Data, Text, Tables, or Figures.

\section{Author details}

${ }^{1}$ Division of Injury Response, National Center for Injury Prevention and Control, Centers for Disease Control and Prevention, 4470 Buford Highway 
NE, MS-F62, Atlanta, GA 30341, USA. ²Vanderbilt University School of Medicine, Nashville, TN, USA.

Received: 6 January 2014 Accepted: 11 April 2014 Published: 02 Jun 2014

\section{References}

Adelson DP, Bratton SL, Carney NA, Chesnut RM, Du Coudray HEM, Goldstein B, Kochanek PM, Miller HC, Partington MD, Selden NR, Warden CR, Wright DW. Guidelines for the acute medical management of severe traumatic brain injury in infants, children, and adolescents. Chapter 2: Trauma systems, pediatric trauma centers, and the neurosurgeon. Pediatr Crit Care Med. 2003; 4(3):S5-8.

American College of Surgeons Committee on Trauma. Resources in Optimal Care of the Injured Patient: ConsultationNerification Program, Reference Guide of Suggested Classification. Chicago, IL: American College of Surgeons; 2006: p. 10-3.

American College of Surgeons Committee on Trauma. National Trauma Data Standard Data Dictionary. Chicago, IL: American College of Surgeons; 2008. Version 1.2.5.

Asemota AO, George BP, Bowman SM, Haider AH, Schneider EB. Causes and trends in traumatic brain injury for United States adolescents. J Neurotrauma. 2013; 30(2):67-75.

Athey J, Dean JM, Ball J, Wiebe R, Melese-d'Hospital I. Ability of hospitals to care for pediatric emergency patients. Pediatr Emerg Care. 2001; 17(3):170-4.

Coronado VG, Xu L, Basavaraju SV, McGuire LC, Wald MM, Faul MD, Guzman BR, Hemphill JD. Surveillance for traumatic brain injury-related deaths United States, 1997-2007. Morbid Mortal Weekly Rep Surveillance Summ. 2011; 60(5):1-32

Cudnik MT, Newgard CD, Sayre MR, Steinberg SM. Level I versus Level II trauma centers: an outcomes-based assessment. J Trauma. 2009; 66(5):1321-6. Available from: http://www.ncbi.nlm.nih.gov/pubmed/19430234.

Deans K, Minneci PC, Lowell W, Groner Jl. Increased morbidity and mortality of traumatic brain injury in victims of nonaccidental trauma. J Trauma Acute Care Surg. 2013; 75(1):157-60.

Densmore JC, Lim HJ, Oldham KT, Guice KS. Outcomes and delivery of care in pediatric injury. J Pediatr Surg. 2006; 41(1):92-8.

Faul MD, Xu L, Wald MM, Coronado VG. Traumatic brain injury in the United States: emergency department visits, hospitalizations and deaths 2002-2006. Atlanta, GA: Centers for Disease Control and Prevention, National Center for Injury Prevention and Control; 2010.

Fortune JB, Sanchez J, Graca L, Haselbarth J, Kuehler DH, Wallace JR, Edge W, Feustel PJ. A pediatric trauma center without a pediatric surgeon: a four-year outcome analysis. J Trauma. 1992; 33(1):130-9.

Gausche-Hill M, Schmitz C, Lewis RJ. Pediatric preparedness of US emergency departments: a 2003 survey. Pediatrics. 2007; 120(6):1229-37.

Haider AH, Chang DC, Efron DT, Haut ER, Crandall M, Cornwell EE. Race and insurance status as risk factors for trauma mortality. Arch Surg. 2008; 143(10):945-9.

Jubelirer RA, Agarwal NN, Beyer FC III, Ferraro PJ, Jacobelli MC, Pfeifer WF III, Shah MA, Welch GW. Pediatric trauma triage: review of 1,307 cases. J Trauma. 1990; 30(12):1544-7.

Kaufmann CR, Rivara FP, Maier RV. Pediatric trauma: need for surgical management. J Trauma. 1989; 29(8):1120-6.

Keenan HT, Bratton SL. Epidemiology and outcomes of pediatric traumatic brain injury. Dev Neurosci. 2006; 28(4-5):256-63.

Knudson MM, Shagoury C, Lewis FR. Can adult trauma surgeons care for injured children? J Trauma. 1992; 32(6):729-38.

Kochanek PM, Carney NA, Adelson PD, Ashwal S, Bell MJ, Bratton S, Carson S, Chesnut RM, Ghajar J, Goldstein B, Grant GA, Kissoon N, Peterson K, Selden NR, Tasker RC, Tong KA, Vavilala MS, Wainwright MS, Warden CR. Guidelines for the acute medical management of severe traumatic brain injury in infants, children, and adolescents - second edition. Pediatr Crit Care Med. 2012; 13(1):S1-82.

Langlois JA, Rutland-Brown W, Thomas KE. Brain injury among children in the United States differences by race. J Head Trauma Rehabil. 2005; 20(3):229-38.

MacKenzie EJ, Rivara FP, Jurkovich GJ, Nathens AB, Frey KP, Egleston BL, Salkever $D S$, Scharfstein DO. A national evaluation of the effect of trauma-center care on mortality. N Engl J Med. 2006; 354(4):366-78.
Mooney DP, Rothstein DH, Forbes PW. Variation in the management of pediatric splenic injuries in the United States. J Trauma. 2006; 61(2):330-3.

Nance ML, Carr BG, Branas CC. Access to pediatric trauma care in the United States. Arch Pediatr and Adolesc Med. 2009; 163(6):512-8.

National Center for Injury Prevention and Control. Report to Congress on Mild Traumatic Brain Injury in the United States: Steps to Prevent a Serious Public Health Problem. Atlanta, GA: Centers for Disease Control and Prevention, National Center for Injury Prevention and Control; 2003.

Osler TM, Vane DW, Tepas JJ, Rogers FB, Shackford SR, Badger GJ. Do pediatric trauma centers have better survival rates than adult trauma centers? An examination of the National Pediatric Trauma Registry. J Trauma. 2001; 50(1):96-101.

Oyetunji TA, Haider AH, Downing SR, Bolorunduro OB, Efron DT, Haut ER, Chang DC, Cornwell EE, Abdullah F, Siram SM. Treatment outcomes of injured children at adult level 1 trauma centers: are there benefits from added specialized care? Am J Surg. 2011; 201(4):445-9.

Potoka DA, Schall LC, Ford HR. Improved functional outcome for severely injured children treated at pediatric trauma centers. J Trauma. 2001; 51:824-34.

Potoka DA, Schall LC, Gardner MJ, Stafford PW, Peitzman AB, Ford HR. Impact of pediatric trauma centers on mortality in a statewide system. J Trauma. 2000; 49(2):237-45.

Pracht EE, Tepas JJ III, Langland-Orban B, Simpson L, Pieper P, Flint LM. Do pediatric patients with trauma in Florida have reduced mortality rates when treated in designated trauma centers? J Ped Surg. 2008; 43:212-21.

Rhodes M, Smith S, Boorse D. Pediatric trauma patients in an "adult" trauma center. J Trauma. 1993; 35(3):384-93.

Rivara FP, Koepsell TD, Wang J, Temkin N, Dorsch A, Vavilala MS, Durbin D, Jaffe KM. Disability 3, 12, and 24 months after traumatic brain injury among children and adolescents. Pediatrics. 2011; 128(5):e1129-38.

Rosen H, Saleh F, Lipsitz SR, Meara JG, Rogers SO. Lack of insurance negatively affects trauma mortality in US children. J Ped Surg [Internet] Elsevier Inc. 2009; 44(10):1952-7. Available from: http://www.ncbi.nlm.nih.gov/pubmed/ 19853754.

Roudsari B, Field C, Caetano R. Clustered and missing data in the US National Trauma Data Bank: implications for analysis. Inj Prev [Internet]. 2008; 14(2):96-100. Available from: http://www.ncbi.nlm.nih.gov/ pubmed/18388229

Sasser SM, Hunt RC, Faul M, Sugerman D, Pearson WS, Dulski T, Wald MM, Jurkovich G, Newgard C, Lerner EB, Cooper A, Wang S, Henry MC, Salomone JP, Galli RL. Guidelines for field triage of injured patients: recommendations of the National Expert Panel on Field Traige, 2011. Morbid Mortal Weekly Rep (MMWR). 2012; 61(1):1-20.

Schneier AJ, Shields BJ, Hostetler SG, Xiang H, Smith GA. Incidence of pediatric traumatic brain injury and associated hospital resource utilization in the United States. Pediatrics. 2006; 118(2):483-92.

Segui-Gomez M, Chang DC, Paidas CN, Jurkovich GJ, MacKenzie EJ, Rivara FP. Pediatric trauma care: an overview of pediatric trauma systems and their practices in 18 US states. J Pediatr Surg. 2003; 38(8):1162-9.

Slomine BS, McCarthy ML, Ding R, MacKenzie EJ, Jaffe KM, Aitken ME, Durbin DR, Christensen JR, Dorsch AM, Paidas CN. Health care utilization and needs after pediatric traumatic brain injury. Pediatrics. 2006; 117(4):e663-74.

Sugerman DE, Xu L, Pearson WS, Faul M. Patients with severe traumatic brain injury transferred to a Level I or II trauma center: United States, 2007 to 2009. J Trauma Acute Care Surg [Internet]. 2012; 73(6):1491-9. Available from: http://www.ncbi.nlm.nih.gov/pubmed/23188242.

Tepas JJ, Leaphart CL, Pieper P, Beaulieu CL, Spierre LR, Tuten JD, Celso BG. The effect of delay in rehabilitation on outcome of severe traumatic brain injury. J Ped Surg. 2009; 44(2):368-72.

Yeates KO, Swift E, Taylor HG, Wade SL, Drotar D, Stancin T, Minich N. Short- and long-term social outcomes following pediatric traumatic brain injury. $J$ Int Neuropsychol Soc. 2004; 10(3):412-26.

\subsection{6/2197-1714-1-15}

Cite this article as: Ovalle et al:: Outcomes of pediatric severe traumatic brain injury patients treated in adult trauma centers with and without added qualifications in pediatrics - United States, 2009. Injury Epidemiology 2014, 1:15 